\title{
Are We Winning the War against Posttraumatic Stress Disorder?
}

\section{Citation}

McNally, Richard J. 2012. Are we winning the war against posttraumatic stress disorder? Science 336(6083): 872-874.

\section{Published Version}

doi:10.1126/science.1222069

\section{Permanent link}

http://nrs.harvard.edu/urn-3:HUL.InstRepos:8916494

\section{Terms of Use}

This article was downloaded from Harvard University's DASH repository, and is made available under the terms and conditions applicable to Open Access Policy Articles, as set forth at http:// nrs.harvard.edu/urn-3:HUL.InstRepos:dash.current.terms-of-use\#OAP

\section{Share Your Story}

The Harvard community has made this article openly available.

Please share how this access benefits you. Submit a story.

Accessibility 


\section{Science (in press)}

Title: Are We Winning the War against Posttraumatic Stress Disorder?

Author: Richard J. McNally $\mathrm{y}^{1}$

Affiliation: ${ }^{1}$ Harvard University

* Correspondence to: Richard J. McNally, Department of Psychology, Harvard University, 33 Kirkland Street, Cambridge, MA 02138 USA. E-mail: rjmewjh.harvard.edu

One Sentence Summary: The rate of posttraumatic stress disorder among veterans of Iraq and Afghanistan is lower than many expected, and efficacious treatments are available for those with PTSD. 


\section{Abstract:}

The most methodologically rigorous epidemiological study on American military personnel deployed to Iraq and Afghanistan found that $4.3 \%$ of troops developed posttraumatic stress disorder (PTSD). Among deployed combatants, 7.6\% developed PTSD, whereas $1.4 \%$ of deployed noncombatants did so. The Department of Veterans Affairs has launched a program ensuring that all veterans with PTSD will receive evidencebased cognitive-behavioral therapy, and the Army has developed the Battlemind postdeployment that reduces risk for the disorder. 


\section{Main Text:}

The outbreak of war in Afghanistan and Iraq prompted dire predictions about its likely psychiatric consequences. The chief of readjustment counseling services at the Department of Veterans Affairs (VA) conjectured that as many as 30\% of troops deployed to Iraq might develop posttraumatic stress disorder (PTSD) (1), a syndrome that can emerge following exposure to horrific, life-threatening events, such as combat, natural disasters, and rape. PTSD sufferers do not merely remember their trauma; they reexperience it as vivid sensory recollections (flashbacks), nightmares, and intrusive thoughts. They feel numb and emotionally disconnected from loved ones, yet also tense, irritable, and hypervigilant as if danger were forever present.

Psychiatry ratified the PTSD diagnosis in 1980, chiefly in response to the belated recognition of its symptoms in Vietnam veterans whose problems had long been inadequately understood and treated. Indeed, the most rigorous epidemiological study ever done on Vietnam veterans had reported that $30.9 \%$ of men who served in this war developed PTSD (2), thereby furnishing a basis for early predictions about PTSD among Iraq veterans. Keen to avoid the mistakes of the Vietnam era, American, British, and Dutch authorities 
launched epidemiological surveys assessing the mental health of troops returning from Iraq and Afghanistan, aiming to ascertain the prevalence of PTSD and enable its early detection and treatment.

\section{The Epidemiology of PTSD.}

A decade later, the data are in, and the implications are surprisingly optimistic. The wars have certainly caused PTSD, but at rates far lower than many had expected. The most methodologically sound surveys have assessed large numbers of military personnel (or veterans) randomly sampled from the overall population of American and British troops who have served in Iraq and Afghanistan. These studies show that the proportion of troops that has developed PTSD ranges from $2.1 \%$ to $13.8 \%$ (3)

The most rigorous study on American troops is the US Millennium Cohort study, a population-based, longitudinal investigation of active duty and Reserve/National Guard personnel (4). It involves random samples representative of the subpopulations of deployed combatants, deployed noncombatants, and nondeployed noncombatants. Hence, it avoids the biases associated with convenience samples or from samples drawn from those seeking treatment. Moreover, the subjects were free of PTSD at baseline, thereby providing 
estimates of PTSD attributable to military trauma alone, not to trauma occurring prior to a soldier's enlistment in the service. Assessing 47,837 members of the Armed Forces, the researchers found that 4.3\% of personnel deployed to Afghanistan or Iraq developed PTSD. Among deployed personnel, $7.6 \%$ of those reporting combat exposure developed the disorder, whereas $1.4 \%$ did so among those not experiencing combat. Of those who had never deployed overseas, 2.3\% developed PTSD in response to stateside trauma (e.g., accidents on military bases). To be sure, rates of 4.3\% among all deployers and $7.6 \%$ among combatants are not trivial. Yet these figures are much lower than the predicted figure of 30\% for all deployed troops, noncombatants as well as combatants $(1,2)$.

A longitudinal study involving a subset of the Millennium Cohort provides further reason for cautious optimism. The researchers assessed PTSD symptoms prior to deployment to Afghanistan or Iraq and at two postdeployment follow-up assessments separated by a three-year interval, enabling them to track the course of symptoms over time. (5) Among single- and multiple-deployers, respectively, $6.7 \%$ and 4.5\% were healthy at baseline, but were symptomatic at both follow-up assessments, suggestive of chronic PTSD directly 
attributable to war. Yet most soldiers deploying either once (83.1\%) or multiple times (84.9\%) were resilient as they exhibited a PTSD-free healthy trajectory across all three assessment points.

One limitation of these surveys is their reliance on questionnaire measures of PTSD. Although cost-effective, this approach can overestimate PTSD relative to the "gold standard" of structured clinical interview. For example, a study of 382 Dutch infantry veterans of Iraq yielded a questionnaire-based rate of PTSD of 21\%, whereas structured interviews involving 339 of them revealed a rate of 4\% (6). Some veterans apparently misunderstood certain questions, answered questions in reference to events unrelated to the war (e.g., receiving upsetting news from home), or experienced insufficient impairment to qualify for the diagnosis. Overestimates are less likely when questionnaire studies require that symptoms surpass stringent severity thresholds and that they produce social and occupational impairment.

\section{The Treatment of PTSD.}

Unexpectedly modest rates of PTSD among recent veterans do not justify complacency about the problem. Regardless of 
the prevalence of PTSD, removing obstacles to prompt, efficacious treatment is essential.

One obstacle is stigma about seeking help for mental health problems, a common concern among active duty troops, especially for those combatants reporting the most symptoms on anonymous surveys. Encouragingly, worries about stigma diminish in military units characterized by strong cohesion and excellent leadership (7) .

Concern about stigma may lessen after personnel separate from the service. Among American veterans of Afghanistan and Iraq seeking any form of health care from the VA, 25\% receive a mental health diagnosis and 52\% of these have PTSD (8). These data indicate that not all mental health problems constitute PTSD; others include depression, alcohol abuse, and difficulties readjusting to family life.

Nevertheless, the importance of PTSD has inspired a landmark VA initiative to ensure that veterans with the disorder receive either prolonged exposure (PE) or cognitive processing therapy (CPT) (9). Both are cognitive-behavioral therapies having the strongest evidential support for treating the disorder, at least among civilian trauma victims. Prior to this initiative, less than 10\% of VA 
clinicians specializing in the treatment of PTSD routinely used PE.

$\mathrm{PE}$ requires patients to recount traumatic memories repeatedly within a structured, supportive therapeutic context until distress declines. In addition to this imaginal exposure component, PE also involves gradual, systematic exposure to feared, but safe, reminders of the trauma in everyday life. CPT has patients recount their traumatic experiences repeatedly in writing. Both $\mathrm{PE}$ and CPT require therapists to identify and help patients' correct maladaptive beliefs about their symptoms and about the trauma.

To ensure widespread dissemination, the VA asked the developers of PE and CPT, Edna B. Foa and Patricia A. Resick, respectively, to oversee training workshops followed by intensive supervision of cases. The original subset of VA clinicians are now themselves training additional therapists, thereby expanding the pool of clinicians equipped to deliver state-of-the-art, evidenced-based CBT. Vital to this endeavor has been administrative support for the program, guaranteed time for therapists to deliver treatment optimally, and incentives and directives to ensure its maintenance. 
Although randomized controlled trials (RCTs) are essential for confirming the efficacy of the program for recent veterans, initial data from one hospital are promising. Of the 66\% of veterans of Iraq and Afghanistan who completed the PE program, 74\% had posttreatment PTSD scores that fell well below the clinical cutoff for PTSD (10). If this study is any indication, veterans of the recent wars may have much better chances of recovery than did veterans of previous wars for whom PE was unavailable.

\section{The Prevention of PTSD.}

The emotional and financial costs of chronic PTSD are substantial. Ideally, it would be better to prevent it than treat it only after it develops. This proactive approach characterizes the Comprehensive Soldier Fitness (CSF) program, delivered to all members of the Army regardless of their occupational specialty (e.g., clerk, combat infantryman). Just as training in boot camp builds physical fitness, CSF aims to build psychological fitness, drawing on principles of positive psychology to cultivate resilience in soldiers (11). Important goals include facilitating personal growth and inculcating skills to reduce risk for PTSD. Moreover, the CSF includes a module to help soldiers and 
their families manage the stress of prolonged deployments overseas (12) .

Unfortunately, the Army implemented the program without first conducting an RCT to test whether CSF reduces the incidence of PTSD. That is, it would have been desirable to randomly assign certain brigades to receive the program, and test whether it reduces rates of PTSD below that of brigades randomly assigned to receive the Army's standard program (13). Without such pilot testing, it will be difficult to tell whether any beneficial outcomes are attributable to CSF. In fact, RCTs have shown that some prevention programs in the mental health field have had unintended adverse consequences (14) .

To say that we ought to prevent PTSD implies that we can do so, and it remains unclear how malleable risk factors for PTSD really are. Because most military personnel do not develop the disorder, one might argue that we should not allocate resources to efforts to prevent PTSD in people unlikely to develop the disorder in the first place, including soldiers whose duties seldom place them in harm's way

Hence, another option is to develop a preventive intervention, test whether it works, and then deliver it to 
high-risk groups. Targeting groups, not individuals, would also diminish the likelihood of stigma. Exemplifying this approach, the Army has developed postdeployment Battlemind debriefing, an early intervention program for preventing psychological problems among platoons returning from combat duty (15). Unlike other debriefing methods that may impede recovery from trauma (16), Battlemind deemphasizes cathartic sharing of trauma stories within the group and focuses instead on the skills needed for a successful transition from the combat zone to home. Group facilitators remind soldiers to trust their training, emphasizing how their mastery of military skills will render them resilient, and they provide tips on coping with the three common concerns of sleep difficulties, anger control, and interpersonal withdrawal.

The Army has also developed postdeployment Battlemind training for larger groups of returning combat units. In this didactic intervention, leaders reframe common difficulties, such as hypervigilance, sleep difficulties, and emotional withdrawal that occur from the transition to home as adaptive combat skills that require adjustment. For example, leaders remind soldiers to apply the emotional bonding skills they used in their combat units to reaffirm 
positive family relationships. They also emphasize positive cognition and coping skills.

An RCT revealed that both postdeployment Battlemind programs produced favorable outcomes at four-month follow-up relative to the Army's standard postdeployment stress education program (15). Soldiers with the most combat exposure received the most benefit, reporting fewer symptoms of PTSD and depression, less difficulty sleeping, and less concern about stigma. Hence, soldiers most at risk for PTSD received the most benefit from this preventive intervention. An RCT testing an anglicized version of postdeployment Battlemind training among UK military personnel returning from Afghanistan reduced binge drinking at six-month followup relative to the standard stress debriefing, but it did not affect PTSD symptoms (17). However, the level of baseline PTSD symptoms was substantially lower than in the American RCT. Hence, there was little room for improvement.

\section{Conclusions.}

Dire predictions notwithstanding, the vast majority of troops deployed to Iraq and Afghanistan have been resilient, and the prospects for recovery for those who have developed PTSD have never been better as the VA ensures that veterans receive the best evidence-based care. Some preventive 
interventions show promise, too. Yet the most hopeful development is the remarkable decline in the frequency, duration, and lethality of war, especially during the past 60 years (18). There are multiple likely causes of this decline (19), but identifying those subject to control is vital for fostering this positive trend. Indeed, steps that further the global decline in violence provide the surest route to preventing PTSD throughout the world today. 


\section{References and Notes:}

1. S. Dentzer, [Interview with Alfonso Batres]. Online News Hour. http://www.pbs.org/newshour/bb/health/ julydec30/batres_extended. Accessed May 3, 2006. (2003).

2. R. A. Kulka, W. E. Schlenger, J. A. Fairbank, R. L. Hough, B. K. Marmar, D. S. Weiss, Trauma and the Vietnam War: Report of Findings from the National Vietnam Veterans Readjustment Study (Brunner/Mazel, New York, 1990)

3. J. Sundin, N. T. Fear, A. Iverson, R. J. Rona, S. Wessely, PTSD after deployment to Iraq: Conflicting rates, conflicting claims. Psychol. Med. 40, 367 (2010).

4. T. C. Smith et al., New onset and persistent symptoms of post-traumatic stress disorder self reported after deployment and combat exposures: Prospective population based US military cohort study. BMJ 336, 366 (2008).

5. G. A. Bonanno et al., Trajectories of trauma symptoms and resilience in deployed U.S. military service members: A prospective cohort study. Br. J. Psychiat. 200, 317 (2012) .

6. I. M. Engelhard et al., Deployment-related stress and trauma in Dutch soldiers returning from Iraq. Br. J. Psychiat. 191, 140 (2007). 
7. K. M. Wright et al., stigma and barriers to care in soldiers postcombat. Psychol. Services 6, 108 (2009).

8. K. H. Seal, D. Bertenthal, C. R., Miner, S. Sen, C. Marmar, Bringing the war back home: Mental health disorders among 103,788 US veterans returning from Iraq and Afghanistan seen at Department of Veterans Affairs facilities. Arch. Internal Med. 167, 476 (2007).

9. B. E. Karlin et al., Dissemination of evidence-based psychological treatments for posttraumatic stress disorder in the Veterans Health Administration. J. Traumatic Stress 23, 663 (2010).

10. P. W. Tuerk et al., Prolonged exposure therapy for combat-related posttraumatic stress disorder: An examination of treatment effectiveness for veterans of the wars in Afghanistan and Iraq. J. Anxiety Dis. 25, 397 (2011).

11. R. Cornum, M. D. Matthews, M. E. P. Seligman, Comprehensive Soldier Fitness: Building resilience in a challenging institutional context. Am. Psychol. 66, 4 (2011) .

12. J. M. Gottman, J. S. Gottman, C. L. Atkins, The Comprehensive Soldier Fitness program: Family skills component. Am. Psychol. 66, 52 (2011). 
13. R. G. Tedeschi, R. J. McNally, Can we facilitate posttraumatic growth in combat veterans? Am. Psychol. 66, 19 (2011).

14. G. A. Bonanno, M. Westphal, A. D. Mancini, Resilience to loss and potential trauma. Annu. Rev. Clin. Psychol. 7, $511(2011)$

15. A. B. Adler, P. D. Bliese, D. McGurk, C. W. Hoge, C. A. Castro, Battlemind Debriefing and Battlemind Training as early interventions with soldiers returning from Iraq: Randomization by platoon. J. Consult. Clin. Psychol. 77, $928(2009)$

16. R. J. McNally, R. A. Bryant, A. Ehlers, Does early psychological intervention promote recovery from posttraumatic stress? Psychol. Sci. Public Interest 4, $45(2003)$

17. K. Mulligan et al., Postdeployment Battlemind Training for the U.K. Armed Forces: A cluster randomized controlled trial. J. Consult. Clin. Psychol. in press. http://psycnet.apa.org/psycinfo/2012-06377-001/

18. J. S. Goldstein, Winning the War on War: The Decline of Armed Conflict Worldwide (Dutton, New York, 2011).

19. S. Pinker, The Better Angels of Our Nature: Why Violence Has Declined (Viking, New York, 2011). 
Acknowledgments: I thank Naomi Breslau, Daniel M. Wegner, and Simon Wessely for helpful comments on previous drafts of this article. 